\title{
Stenting of Coarctation of Aorta in a Post Device Closure of Patent Ductus Arteriosus and Balloon Coarctoplasty patient: A Case Report
}

\author{
Nurun NaharFatema, Ferdousur Rahman Sarker \\ Department of Pediatrics and Pediatric Cardiology, Combined Military Hospital, Dhaka
}

\begin{abstract}
:
Key Words : Coarctation of aorta, Patent ductus arteriosus, congenital heart disease, device closure, Intravascular stent treatment of coarctation of Aorta has proved successful in 96-98\% cases. The decision as to which method should be utilized for treatment of coarctation, out of the option of surgical, balloon angioplasty and stent implantation is still controversial in our center. We do balloon angioplasty for majority of cases as stents are expensive and patients are very young. Here we are reporting a case who had device closure of patent ductus arteriosus (PDA) 3 month ago along with balloon angioplasty of coarctation. But patient developed re coarctation within one month and then intravascular stent was implanted.
\end{abstract}

percutaneous

intervention.

(Cardiovasc. j. 2016; 9(1): 64-67)

\section{Introduction:}

Endovascular treatment of native and recurrent coarctation of aorta gained a widespread acceptance since the mid $1990 \mathrm{~s}$, especially in adolescents and adults. ${ }^{1}$ There has been a change recently to stent implantation from balloon dilatation technique. Balloon dilatation may cause intimal and sometime medial injury which leads to restenosis and aneurysmal disease. ${ }^{2.3}$ Stenting of aorta gives radial support to vessel wall and apposes intima to media which also helps in redilatation of vessel in future if needed.

The success rate of the procedure is usually around $90 \%$ and results are satisfactory in the term if increase in diameters of coarct segment, decrease in gradient across coarct segment and also reduction in systemic hypertension. There may be some complication related to stent implantation which includes aneurysm formation, restenosis, stent recoil and stent fracture. Re-dilatation or new stent implantation may be required in these situations. We perform Coarctation stenting routinely in patient weighting more than $15 \mathrm{~kg}$ unless there is no other contraindication.

\section{Case report:}

M, a 4 years old male child was diagnosed as a case of patent ductus arteriosus and severe coarctation of aorta 3 months ago. He had history of exertional dyspnoea of grade II. A murmur was detected during examination and referred to pediatric cardiologist for work up.

His blood pressure were measured and upper limb pressure was 140/85 $\mathrm{mmHg}$ and lower limb pressure was 100/75 $\mathrm{mmHg}$. So gradient was noticed and femoral pulse was feeble also. His chest x-ray showed cardiomegaly and ECG showed left ventricular hypertrophy. Echocardiography showed a large PDA of $3.5 \mathrm{~mm}$ size with severe coarctation of aorta. Gradient across coarctation segment was $55 \mathrm{mmHg}$.

On $15^{\text {th }}$ may 2015 he was taken into the catheterization laboratory of CMH Dhaka and device closure of PDA was performed with 10x8mm (Cera) device. Balloon angioplasty of coarctation was performed also with a $10 \mathrm{~mm} \times 2 \mathrm{~cm}$ 'Tyshak' balloon. After procedure no gradient was noticed across the coarctation segment. Patient was discharged after 72 hours. In 24 hours follow up, echocardiography showed residual-coarctation with gradient of $20 \mathrm{~mm} \mathrm{Hg}$ across coarct segment. Patient was advised to come after one month and echocardiography this time showed severe coarctation with gradient across coarct segment of $60 \mathrm{mmHg}$.

Address of correspondence: Prof. Nurun Nahar Fatema, Department of Pediatrics and Pediatric Cardiology Combined Military Hospital, Dhaka, Bangladesh. Email: colfatema@hotmail.com 
Echo also showed mild pericardial effusion and borderline LV function with dilated LV. CT angiogram of Aorta showed discrete severe coarctation. Patient weight was $11 \mathrm{~kg}$. But we decided for stenting with Advanta $\mathrm{V}_{12}$ covered stent. M was taken into cath lab on $27^{\text {th }}$ July 2015.

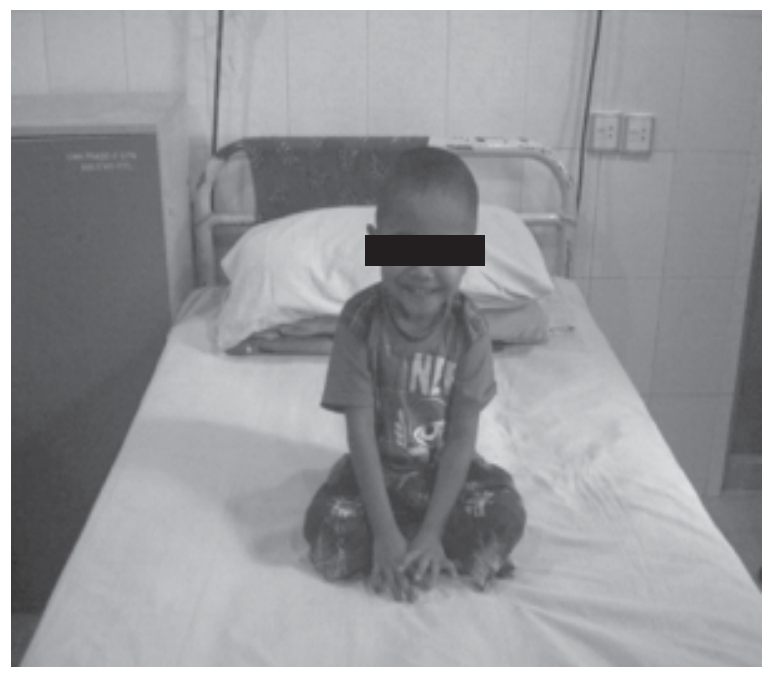

Fig.-1: Patient M after implantation of stent.

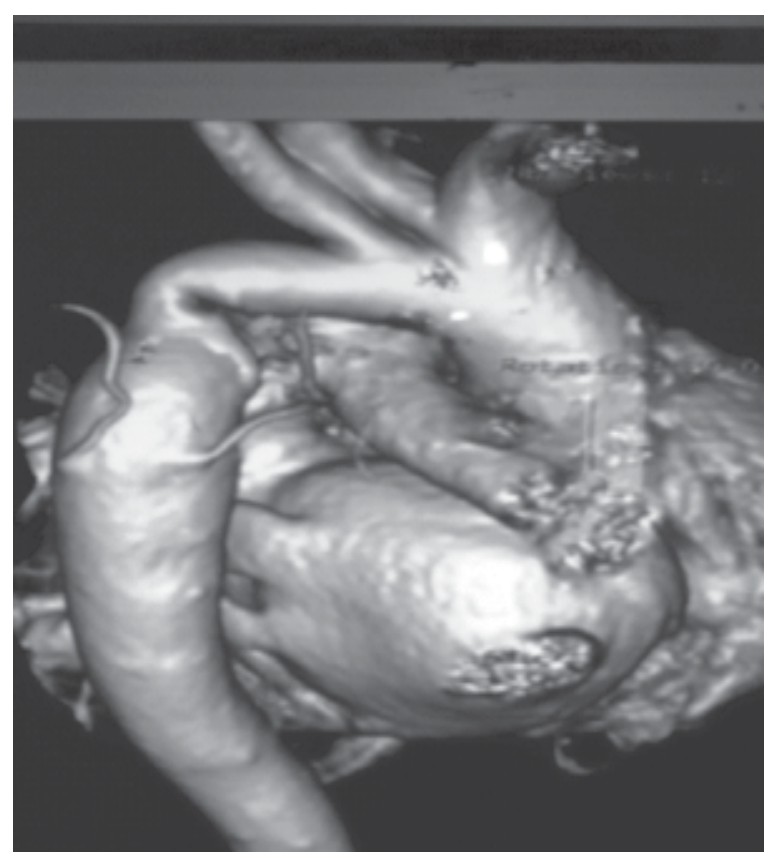

Fig.-2: CT- Aortogram showing severe discrete Coarctation of Aorta.

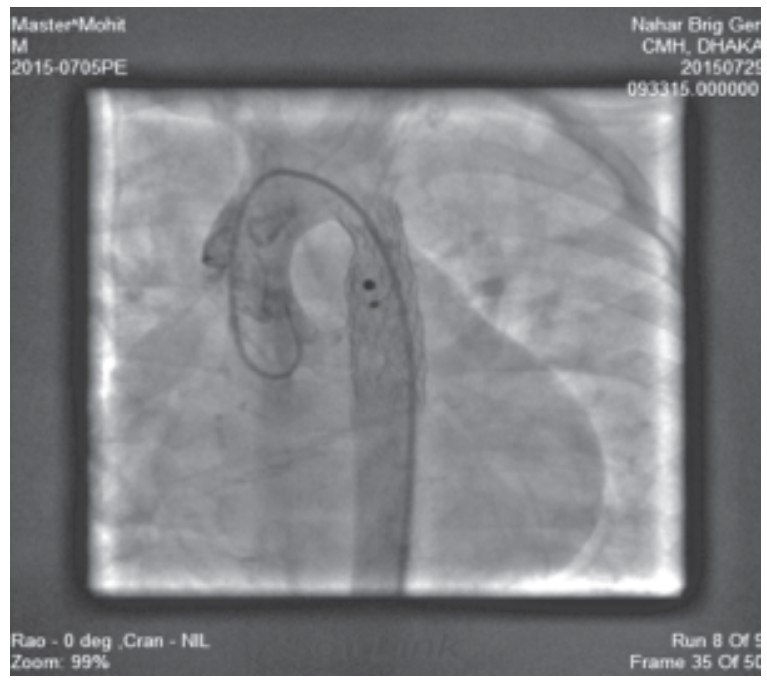

Fig.-3: Aortogram after implantation of stent.

\section{Procedure:}

Patient was sedated with injection ketamine and midazolam. Than patient was dropped and right femoral venous and arterial line was established. Aortogram showed PDA device in position with little protruded aortic end of ADO-1. Balloon dilatation with $8 \mathrm{~mm} \times 2.0 \mathrm{~cm}$ balloon was performed once. Diameter of Aortic arch, Isthmus and descending aorta near diaphragm measured. Diameter near transverse aortic arch was $11 \mathrm{~mm}$. A $12 \mathrm{~mm}$ x $36 \mathrm{~mm}$ Advanta $\mathrm{V}_{12}$ stent selected for implantation in coarct segment.

A 0.35 wire was placed in ascending aorta through a multipurpose catheter. A Mullin sheath of $9 \mathrm{f}$ size was placed crossing coarct segment. Balloon mounted stent was forwarded over the wire to coarct segment and inflated up to 11 ATM to dilate it up to $12.5 \mathrm{~mm}$. Post inflation pressure above and below the isthmus was measured. It was zero after procedure. Patient's hemodynamics were stable throughout procedure. Heart rate was increased to 200beats/min during balloon dilatation with Injection Atropine. Patient was shifted to Paediatric cardiac ICU after hemostasis and heparin infusion was continued for 48 hours. Tab. Aspirin $5 \mathrm{mg} / \mathrm{kg}$ started and advised to continue for 6 months. Injection-Ceftriaxone $50 \mathrm{mg} / \mathrm{kg}$ IV was given during the procedure and then once daily for 72 hours. Patient was discharged 72 hours after procedure. He was advised to come for follow up after 1 month. 


\section{Discussion:}

Coarctation of Aorta (CoA) occurred in 5\% of all congenital heart disease. ${ }^{1}$ Coarctation of aorta is typically discrete stenosis in the upper thoracic aorta, at or near the insertion of the ductus arteriosus. The anatomy of coarctation includes intimal and medial malformation and a posterior infolding of these two layers. Coarctation of aorta associated with isthmus or arch hypoplasia or it may be long segment or tortuous. ${ }^{2}$

Balloon dilatation has gained acceptance in the treatment of native and recurrent coarctation but significant number of cases develop re coarctation after balloon angioplasty. ${ }^{3,4}$ This is related to elastic recoil of the vessel. Stent provide radial strength to avoid recoil of the vessel and frame work for endothelial growth. ${ }^{5}$ Stents are gaining popularity in treating coarctation over last few years. But there are some limitations of stents also which includes flexibility, large delivery system to introduce into child or young adult, ability to further re-dilatation to adult size, radial strength, sharp edges, ability to reposition, allowing access to side branch for covered stentetc. ${ }^{6-8}$

The advancement of stent technology aimed to address these desirable characteristics. The most commonly used stent is the balloon expandable stent which allows further expansion of the stent as patient grows. Commonly used stents and Cheathum (CP) covered stents, Advanta $\mathrm{V}_{12}$ Atrium stents, Palmaz stents, Intrastents etc. ${ }^{9-12}$ In our patient we used Atrium v ${ }_{12}$ Advanta 12x36 mm balloon expandable stent.

It is well established that Doppler Echocardiography is the gold standard to diagnose severity and location of coarctation of the aorta. MRI is a good alternative and reliable non-invasive method to depict aortic arch anatomy. Cine MRI and post contrast record allow finding high velocity Jet, peaking systolic velocity and qualification.

CT scan is also used to calculate aortic diameter and is recommended in patient with pacemaker, defibrillator, prosthesis, clips etc. We did CT angiography as MRI machine was out of order in our hospital. This procedure is usually done under general anesthesia but we performed under deep sedation.
The choice of stent diameter and length is a major concern for stent implantation. The stent must cover the coarctation segment without protrusion into left subclavian artery. Stent diameter based mainly on transverse or distal arch diameter or diameter of proximal Aorta. Usually stent selected are 1-2 mm more in size. In our case transverse arch was $11 \mathrm{~mm}$ and we selected $12 \mathrm{~mm}$ stent. Descending aorta diameter at the level of diaphragm was $12 \mathrm{~mm}$. Ratio of expansion of coarctation segment is around 2 to 3.5 and should be $<3.5$.

The stent implantation is considered successful if residual gradient is $<10 \mathrm{~mm} \mathrm{Hg}$. In our case it was $0 \mathrm{mmHg}$ immediately after the procedure. The most serious complication of stenting is rupture of aorta which may lead to death; others are stent migration, stent fracture, aneurysm formation, embolization of stent etc. Restenosis is another issue which has been reported in $13-31 \%$ cases. Comparison between surgery and stenting showed lower morbidity (9\%) in stent group to $11 \%$ in surgery group. ${ }^{13}$

\section{Conclusion:}

Patient with coarctation of aorta have a high risk of late cardiovascular morbidity and mortality mainly related to systemic hypertension. Other potential complications include coronary artery disease, sudden cardiac death, heart failure and stroke. So these patients should be treated immediately after diagnosis. Coarctoplasty with stenting is a safe and effective modality of treatment for these group of patients.

\section{Conflict of Interest - None.}

\section{Reference:}

1. E.V. Krieger, K. Stout. The adult with repaired coarctation of aorta. Heart 2010; 96: 1676-1681.

2. Blackford LM. Coarctation of Aorta. Arch Intern Med 1928; 41:702-735.

3. S Tyagi, R Arora, UA Kaul, KK Sethi, DS Ghambhir, M Khalilullah. Balloon angioplasty of native coarctation of the aorta in adolescents and young adult. Am Heart J 1992;123:674-680.

4. AB Golden, WE Hellenbrand. Coarctation of aorta: Stenting in children and adult. Catheter Cardiovasc Interv 2007;69: 289-299.

5. Abbott ME. Statistical study and historical retrospect of 200 recorded cases with autopsy of stenosis or 
obliteration of the descending arch in subjects above age two years. Am Heart J 1928;3:392-421.

6. Fowzy ME, Dunn B, Galal O. Balloon coarctation angioplasty in adolescents and adults: Early and intermediate results. Am Heart J 1992; 124: 167-171.

7. J Koerselman, H de Vries, W Jaarsma, L Muyldermans, J.M Ernst, HW Plokker. Balloon angioplasty of coarctation of the aorta: a safe alternative for surgery in adults: Immediate and midterm results. Catheter Cardiovasc Interv 2000;50:28-33.

8. TJ Forbes, P Moore, CA Pedra. Intermediate follow up following intravascular stenting of treatment of coarctation of aorta. Catheter Cardiovasc Interv 2007;70:569-577.

9. M Chessa, M Carroza, G Butera, G Butera. Results and mid -long term follow up of stent implantation for native and recurrent coarctation of the aorta. Eur Heart $J$ 2005;26: $2728-2732$.

10. M Ledensa, C Alva, FD Gomez. Results of stenting of coarctation. Am J Cardiol 2001;88: 460-462.

11. Gersony WM. Coarctation of the Aorta. In: Adams FH, Emmanouilides GC, Riemenschneider TA, editors. Heart disease in Infants, children and Adolescents. $4^{\text {th }}$ ed. Baltimone: William \& Wilkins; 1989: 243-255.

12. Arjos R, Qureshi SA, Rosenthal E, Murdoch I, Hayes A, Parsons J, et al. Determinants of haemodynamic results of balloon dilatation of aortic recoarctation. Am J Cardiol 1992; 69: $665-671$.

13. Ovaert C, Benson LN, Nykanen D, Freedom RM. Trans catheter treatment of coarctation of the aorta: a review. Pediatr Cardiol 1998;19: 27-44 (Pubmed). 